\section{Consequences of nuclear warfare}

SIR - Nature has from time to time criticized individual scientists and groups of scientists for their activities in behalf of peace and disarmament, especially in respect to nuclear weapons. But even this back-ground left us unprepared for the tone and content of Vera Rich's article (28 October 1982, p. 769). Basing herself on an article by $E$. Teller published in Reader's Digest, she endeavours to represent nuclear war as somehow survivable and thus perhaps not so different from preHiroshima warfare. She speaks of a "swift return to quasi-normality after nuclear bombardment". Referring to Teller's Reader's Digest article she writes that " $[\mathrm{He}]$ attempts to refute some of the more fantastic myths of what nuclear war would entail. [He quotes] instances from Hiroshima and Nagasaki: 'bridges open ... a day after the blast, trains ran on the second day, streetcars. . . on the third"'.

Her terminology "fantastic myths" betrays her own outlook. It betrays also a failure to understand some indisputable and obvious aspects of the situation. Now, unlike in the days of Hiroshima and Nagasaki, huge numbers of nuclear bombs could saturate a whole country. This is the age of the new word "overkill". Hiroshima and Nagasaki, hit by what would be very small bombs, could receive aid from elsewhere. Now there would be no elsewhere. The utter destruction which would ensue would permit no return to Rich's "quasi-normality".

Rather than taking as authoritative an article published by a single American physicist in Reader's Digest, we would rely upon the resolution adopted virtually unanimously by the (US) National Academy of Sciences (regrettably never published in Nature) on 27 April 1982. We cite only two of its findings: "science offers no prospect of effective defense against nuclear war and mutual destruction, . . . a general nuclear war could kill hundreds of millions and destroy civilization as we know it".

Unanimous endorsement for the entire resolution came in June 1982, from the Executive Committee of the American Physical Society and also from the Academy of Sciences of the Royal Society of Canada.

Eminent physicians have made it absolutely clear that the health care delivery systems would be destroyed by a nuclear bombardment. Death would be widespread. Those who survived the explosion would suffer horribly until their brief post-bomb existence ended.

This was agreed unanimously and documented scientifically by a panel led on the US side by Professor Lowns of Harvard and on the Soviet side by Academician Chazov, Deputy Minister of Health of the
Soviet Union. The panel was televised nationally by the Soviet television network and in the United States by the Public Broadcasting System. Information concerning transcripts is available from the Public Broadcasting System, 609 Fifth Avenue, New York, NY 10017, USA.

\section{ED BARBEAU \\ ERIC FAWCETT \\ TERRY GARDNER \\ BRYDON GOMBAY \\ LEE LORCH \\ DEREK MANCHESTER \\ DeREK PAUL \\ METTA SPENCER \\ LYNN TRAINOR}

(Directors, Science for Peace)

Science for Peace,

Physics Department,

University of Toronto,

Toronto, Canada

VERA Rich's article was not based.on Teller's Reader's Digest article but on a TASS complaint thereat - Editor Nature

\section{Asteroids or comets}

SIR - I appreciate Peter Smith's comments on the rigid anti-catastrophism in geological thinking ( Nature 300, 217; 1982). However, he erred in attributing to Alvarez et al. the idea of a terminal Cretaceous cometary impact.

In fact, those authors postulated asteroid impacts, and argued strongly against the cometary idea, which was suggested by $H$. Urey ( Nature 242, 32, 1973) and more recently by myself (Nature $285,201,1980)$. The two scenarios are fundamentally different; one postulated instant extinction $\left(10^{\circ} \mathrm{yr}\right)$, the other less catastrophic $\left(10^{4} \mathrm{yr}\right)$.

KEN HSU

Eidgenossische Technische Hochschule, Zurich, Switzerland

\section{Alternate culture}

SIR - Both the authors (L. LeShan, $H$. Margenau) and the reviewer (M. Jahoda) of the book Einstein's Space and Van Gogh's Sky ( Nature 25 November 1982, p.385) clearly think that the word "alternate" has the same meaning as "alternative".

Since the battle to preserve the clear and valuable distinction between the meanings of these words has already been lost in the United States, it is probably too late to arrest, in this particular, the slide towards illiteracy in this country. However, your journal enjoys a wide circulation, so that my plea that scientists should occasionally consult their dictionaries may hopefully have some effect.

Department of Mathematics,

D.F. LAWDEN

University of Aston,

Birmingham, UK

\section{Polywater reviewed}

SIR - I have only now managed to obtain Felix Franks' book Polywater, published over a year ago (see Nature 5 November 1981)!.

Even the picture on the cover reveals the intention of the author to show that the story of the investigation of polymeric water can be compared with a burst soap bubble. The book pays little attention to the scientific objective of the investigation proper, to its genesis, or to the results obtained.

In his book, Dr Franks appears arrogant enough to judge and teach, but much of what he writes proves incompatible with such a pretension. In describing the negative aspects of the subject the author exhaustively uses the popular press, including newspapers, while disregarding a number of serious scientific journals. Thus, on page 134 he writes: "Yeland Allen and Peter Kollman stated quite explicitly that the position they now adopted was: 'clearly opposite to that in our original work'. During the whole polywater controversy this was the only (sic) honest statement by a group of workers that their own new findings had forced them to change their mind. Their article in Nature of 22 October, 1971 [ref.2] contains no equivocations, no ambiguities, and no question marks"'

Further on, on page 190 (see also page 140), the author writes, in complete contradiction with reality: "The manner in which Derjaguin wrote off ten years of work and publicity in two sentences (sic) was not easy to accept for those who had followed him, and led to some bitter criticism. Derjaguin, however, was geographically inaccessible. ..."

Inaccessible? Foreign scientists each year visit my department at the Institute of Physical Chemistry of the USSR Academy of Sciences, and we have received as guests Langmuir, La Mer, De Boer, $A$. Zettlemoyer, B. Pethica (twice), Parfitt and many others.

Anyone consulting our publications on the matter ${ }^{3}$ should be convinced that the above accusations are untrue. A study of our papers in Doklady Akademii Nauk (including the English edition) and cited in Nature, covering the detailed analysis of the composition of anomalous columns of water, shows that we did not repeat work carried out by other authors at an earlier date. (Delays in obtaining the final results in our laboratory were connected with problems in gaining access to certain items of equipment such as an electron probe.)

Samples of polywater obtained by about ten different techniques have been subjected to analysis. In a number of cases, $\mathrm{Si}$ and $\mathrm{O}_{2}$ were found to be the only admixtures, proving that those samples were products of leaching of quartz in the water condensate. This is the most reliable confirmation of the need to explain why 
the dissolving power of water formed by condensation of vapour is many times greater than that of liquid water at the same temperature.

One possible cause was identified in the work of M. Prigogine and J. Fripiat4. Nonetheless, in his book, F. Franks completely disregards the essence of the ingenious and seriously substantiated explanation as presented by $M$. Prigogine and he expresses (on page 141) his atonishment at this explanation (first published in 19714, and more fully detailed in ref.5). Franks considers it wrong to substantiate this explanation by performing the experiment in conditions favouring the appearance of the anomalous condensate. I find criticism of this kind astonishing.

In order to support his analogy with a burst bubble, Dr Franks has apparently tried to suppress even a hint to the positive results of those investigations. However, in a volume edited by Franks himself, as well as in the Adamson's course of lectures on "Physical Chemistry of Interfaces") those positive results are distinctly formulated. Among such results is the discovery that violations of the capillary condensation equation, which have been detected not only by Fedyakin but even earlier by Patrick, Wilsdon, Shereshevskii, Chmutov and others, are actually caused by dissolved admixtures (and only partly by the adsorption layers close to the liquid meniscus, taken into account in my work).

For an author undertaking to present an objective view of the problem, and emphasizing in support his noninvolvement in the investigation of polywater, his competence and goodwill (see page viii), it is unpardonable of him to write that the discovery of the phenomenon of the anomalous formation of columns is exclusively due to Fedyakin (see page 130), and that I appropriated Fedyakin's discovery (sic) (see page 184). In fact the previously cited paper by Clifford contains quite a different statement (see page 109): "Certainly in 1934 Wilsdon discovered that the properties of water in glass capillaries, and particularly its vapour pressure, depended on whether the water is introduced from the vapour or the liquid phase. However, the systematic study of the anomalous properties of water condensed in glass capillaries or quartz capillaries begins with the rediscovery of the phenomenon by Fedyakin in 196162"'.

I have continued those investigations together with Fedyakin and many other colleagues, continuously citing Fedyakin's earlier papers. See also page 49 of the book, for my version of the matter.

Franks seems sorry that 'Derjaguin, however, was geographically inaccessible"'. In order to help the matter, Franks assumes the role of a detective. Unhindered by the "geographical remoteness", he writes (page 191): "The fate of Zhelezhny, another of Derjaguin's junior colleagues, is a classic in the 'Catch 22' tradition. After taking part in the early experiments, he was worried about the possibilities of impurities in the anomalous water and, on his own initiative, submitted a sample to an East German spectroscopist (anonymous, B.D.) for analysis. The results indicated appreciable levels of impurities. . . Derjaguin did not consider these experimental findings worthy of note in his reports. However, Zhelezhny's name was omitted from all further papers describing research on anomalous water. . Zhelezhny was held responsible for not having done his job properly. He disappeared from his post at the Physical Chemistry Institute in Moscow. . ."

This deserves to be called a slanderous speculation. The scenario outlined bears little relation to the actual events. I would like to add that while being employed at the Physical Chemistry Institute, in the Surface Phenomena Department directed by me, Zhelezhny - after having done his "criminal" has written and defended a $P h D$ thesis and completed a considerable part of his DSci. dissertation. Indeed, he "disappeared" from our institute, but then he similarly disappeared from two others in Leningrad and Moscow.

A logical question now is whether Franks has the right to judge and teach ethical and scientific norms to other scientists, and where in reality lies the socalled "pathology" of science. And finally, I should like to summarize (see Clifford's paper ${ }^{6}$ ) the positive significance of the research in "polywater". Had this research not been carried out, and the role of dissolved substances not been revealed and thoroughly studied, then the WildsonShereshevski-Chmutov-Fedyakin phenomenon would remain a mystery, and the phenomenon of an enhanced solubility, which is observed during the condensation of water vapour, would remain unknown (it could, of course, be surmised from the practice of purification of chemical vessels by vapour treatment).

The work on "polywater" also stimulated the theoretical investigation of the structure of water on the basis of quantum-chemical computations (such as the work of Allen et al.). In conclusion, I point out that the opinions presented on pages 188-189 of Fransks' book (without reference to names), do not correspond to reality; he says that "For instance, the group at Birkbeck College, themselves among the first 'activists' in 1967, suggested several years later that Derjaguin's discovery had been taken seriously not so much because of its intrinsic merit but mostly because of Derjaguin's professional standing as a member of the elite. They then expressed the view that 'much of the published work since then is careless, inconclusive, and often misleading, if not wholly conjectural'."

In fact, in spite of my publications of 1962-67, an explosion of active interest in research in polywater took place only in 1969, when those "misleading works" had been repeated by many scientists.

Thus, there is no reason to consider the naivety of the scientists (see also page 68) as the cause of that interest. It would be more correct to say that nature prepared a malicious surprise. Of course, it is easy in retrospect to recognize the errors made by those doing research in a new field, and then to slap on the label "pathological science" (see Chapter 10).

Such retrospective findings comprise also $D$. Eisenberg's assertion contained in his review of F. Franks' book in Science: "Astonishingly few of the polywater scientists considered the implications of thermodynamics, even though they lead to an immediate negative conclusion on polywater. Since polywater has a lower vapour pressure than ordinary water, with which it is in equilibrium through the vapour phase, it follows from the first and second laws of thermodynamics that the polymer is a stabler form".

This reasoning ignores that in our experiments we have measured not the pressure of the polywater vapour, but that of a solution of a very weakly volatile "anomalous component" in the normal water. A reduced vapour pressure of that solution is in agreement with Raoul's equation. As regards the anomalous component itself, we have supposed (and still believe) that the products of its evaporation are not the molecules of ordinary water; therefore, there is no reason to believe that I and other scientists have ignored the second law of thermodynamics.

In conclusion, I'd like to point out that it is always safer to insure oneself against errors by working within an accepted field, without incurring the risk involved in scientific "pioneering"'. In this connection, having put forward the concept on the structural peculiarities of the boundary layers of liquids tens and hundreds molecules thick as early as the 1930s, I have continuously met with scepticism. Recognition of my work in this specific field has come only after more than 35 years. It was a paper by the prominent English scientist, W. Hardy ${ }^{8}$, that urged me to make those investigations in spite of the fact that the attempt at experimental substantiation, as undertaken by $W$. Hardy, proved to be grossly erroneous.

\section{B. DERJAGUIN}

Institute of Physical Chemistry of the

USSR Academy of Physical Sciences, Moscow, USSR

. Ubell, $R$, Nature 294, 28 (1981)

2. Derjaguin, B.V. \& Churaev, N. Nature phys. Sci 232,131 (1971).

Derjaguin, B. \& Churaev, N.V.Nature 244, (1973); J. Colloid Interface Sci. (1974).

Prigogine, M. \& Fripiat, J. Chem. phys, Lell. 12, 107 (1971) . Prigogine, $M$. thesis.

. Clifford, p.120, Ch.S in Water led. Frank, F.).;

Eisenberg, D. Science 213, 1104 (1981)

8. Hardy, W. Boundary State (193I) 